\title{
Comparing methods for determining flow routing parameters in models that underpin water resource planning in the Murray Darling Basin
}

\author{
$\underline{\text { Alice E. Brown }}^{\mathrm{a}}$, Andrew J. Davidson ${ }^{\mathrm{b}}$, Chas Egan ${ }^{\mathrm{c}}$, Alistair Korn ${ }^{\mathrm{d}}$, Simon Gallant ${ }^{\mathrm{a}}$ \\ ${ }^{a}$ CSIRO Land and Water, Canberra, ${ }^{b}$ NSW Department of Primary Industries: Water, ${ }^{c}$ Department of \\ Science, Information Technology and Innovation, ${ }^{d}$ Murray Darling Basin Authority \\ Email:alistair.korn@mdba.gov.au
}

\begin{abstract}
Hydrological models are used to underpin different policy and management decisions in our regulated river systems. Historically, in Australia, different water management agencies have used different modelling platforms and different approaches to calibrate the models the underpin water resource planning. However, recently these agencies have been working collaboratively to build a standard modelling platform (eWater Source) to support water resource planning. As part of this move to a standard modelling platform, it is recognised that it would be useful to compare the different methods used for model calibration. The aim of this comparison is to determine if: (a) the method of calibration impacts on the predictive capability of the model; and (b) if it is possible to recommend a consistent method that can be applied across all river reaches during calibration of river system models in the Murray Darling Basin. The use of an identical approach allows other river modellers to more easily understand how the model parameters are derived. When building a river system model, the parameters of the flow routing component need to be calibrated, these parameters simulate the timing and shape of the hydrograph at the downstream gauge.

This paper compares different methods for setting the parameters (index flows and travel times) of variable parameter Muskingum routing approach within eWater Source. Three methods for selecting index flows and four methods for determining the travel times are compared over 14 catchments within the Murray Darling Basin. Based on the work of Close (1996), a maximum of 10 index flows have been defined for each method for each reach and the inflow bias has been set to 1 . The three methods for selecting index flows are:
\end{abstract}

1. Manual selection of index flows

2. An automated approach based on changes in the slope of the upstream rating curve

3. Fixed interval index flows

The four methods used to determine the travel time are:

1. Optimisation using $\mathrm{R}$ (Pearson correlation coefficient) as an objective function

2. Optimisation using the $\mathrm{R}$ of the $\log$ of the flow values as an objective function

3. Automated selection of travel time based on analysis peaks at the upstream and downstream flow gauges (using the median travel time of the flows with $10 \%$ of the index flows)

4. Automated selection of travel time based on analysis peaks at the upstream and downstream flow gauges (using the mean travel time of the flows with $10 \%$ of the index flows)

Combined the two sets, results in a total of 12 different methods. The methods were tested using a 2 fold approach and the skill of the methods at making predictions during validation are compared. Using $\mathrm{R}$ as a metric, skills scores (Murphy, 1988) were developed to compare the methods to a benchmark model which only considers lag. Comparing the methods using the Student's t-test, we show that at the 0.01 level there is no statistical difference between any of the methods. However, at the 0.05 level, three of the approaches are statically different when compared to the method with the highest skills score (Manual selection of index flow and optimisation using $\mathrm{R}$ as an objective). Of these three methods that show a difference at the 0.05 level, two of these methods used fixed intervals for the index flows, while all three are based on an analysis of peaks.

The results indicate that using optimisation makes a marginal difference to the predictive capability based on a comparison of the $\mathrm{R}$ values. It also indicates that reasonable predictions can be made via both optimisation or analysis of peaks provides appropriate index flows are selected.

Keywords: Hydrologic routing, Murray Darling Basin, eWater Source 


\section{INTRODUCTION}

As part of the implementation of the eWater Source modelling platform across the Murray Darling Basin (MDB), the Murray Darling Basin Authority (MDBA), CSIRO and the state jurisdictions are working together to develop a series of practice notes aimed to standardise the implementation of eWater Source (Welsh, et al., 2012). These practice notes detail the general principles that should be followed when Source models being conceptualised, built, calibrated and used for assessing the impact of different infrastructure or policy decisions on water availability and water users. Each practice note addresses one aspect of model development and aims to outline the general principles that should be followed when undertaking a particular aspect of modelling. In many cases, it is possible to get agreement between hydrologists across the different organisations on the general principles that should be followed. However, when it comes to implementation of these principles, methods differ and an agreement on a preferred method can be hard to reach. The development and calibration of models has traditionally been undertaken manually based on visual inspection of observed and simulated hydrographs (Hogue, et al., 2000). In order to make models more transparent and consistent, testing of alternate methods for the different components of a river reach model calibration allows us to determine how robust different methods are in making predictions over a range of conditions. This testing requires us to look at the predictive skill (Murphy, 1988) of the different modelling approaches to determine if one approach consistently gives better outcomes compared to other approaches during validation. It is possible that the choice of method makes little difference to the modelling outcome, however, in the case of the different components of a river system model, the alternative methods used by different hydrologists have never been compared in a consistent manner.

When calibrating a reach of the river system there are a large number of water balance components that need to be considered. The prediction of downstream flow is determined based on the routing of the upstream flow, plus explicit gains (e.g. tributary inflows), explicit losses (e.g. irrigation diversions, net evaporation) and any unaccounted difference (Hughes, et al., 2014). The estimation of the different components impacts on how we understand and interpret the water balance of a reach and can potentially impact water management decisions. This paper looks at the calibration of reach routing parameters. These parameters are used to represent the attenuation and timing of flows at the downstream gauge. In addition to the flow and travel time, a dead storage parameter is used to calibrate salinity (Fernando et al. 2007), the calibration of salinity is not considered in this paper.

To compare and contrast different methods of setting routing parameters, it was important to understand what the jurisdictions across the Murray Darling Basin are using or planning to use as they develop models in eWater Source and the methods they are interested in investigating are part of testing. During discussions with key stakeholders it was decided to focus a comparison on different methods for setting variable parameter Muskingum routing (Close, 1996), with an emphasis on the value of using optimisation to determine the piecewise relationship, compared to determining travel times via an analysis of the peaks in different flow ranges.

The use of variable parameter Muskingum routing represents the approach outlined in Close (1996) and is consistent with what MDBA has used in their modelling in the Murray and Lower Darling River System. This approach, requires travel times to be set for different index flows and allows for different storage behaviour within channel and overbank. Traditionally, these parameters would have been determined manually by looking at the travel time for peaks in different flow ranges, however optimisation is being increasing used to set these parameters. This paper compares different approaches for determining the relationship between flow and travel time for routing calibration using 14 test reaches and looks at three different approaches to determine the index flows and four different approaches for determining travel time.

\section{STUDY AREA}

Fourteen test reaches were selected in consultation with key stakeholders. These reaches cover a range of different conditions and complexity found in the Murray Darling Basin. Four reaches have been selected within the existing eWater Source model of the Murray and Lower Darling System, these reaches were chosen to represent different levels of reach complexity and data availability across a highly regulated system. To allow comparison with the paper of Wong \& Laurenson (1983), four of the six reaches used in that study have been included in our test reaches. These reaches are from the Murrumbidgee and Darling River Systems. In addition, three reaches in the Namoi Valley, one from each of the Goulburn, Condamine-Balonne, and Macintyre Brook have been included in the test reaches. There locations are shown in Figure 1. Each reach consists of either a single or multiple upstream and downstream gauging station defining the reach extents. The reaches are listed in Table 1. 
Table 1. Test reaches detailing relevant gauging locations.

\begin{tabular}{lll}
\hline Reach & Upstream Gauge & Downstream Gauge \\
\hline 1 & 409017 (River Murray @ Doctors Point) & 409002 (River Murray @ Corowa) \\
2 & 409025 (River Murray @ DS Yarrawonga) & 409202 (River Murray @ Tocumwal) \\
3 & 409048 (Niemur River @ Barham-Wakool Rd) & 409086 (Niemur River @ Mallan School) \\
4 & River Murray @ Wentworth (425010) & Lock 9 \\
5 & M/Bidgee @ Gundagai (410004) & M/Bidgee @ Wagga (4100001) \\
6 & M/Bidgee R @ Wagga (410001) & M/Bidgee R @ Narrandera (410005) \\
7 & M/Bidgee R @ Narrandera (410005) & M/Bidgee R Darl/Gton P (410021) \\
8 & Darling@Burke Town (425003) & Darling@Wilcannia Main Channel (425008) \\
& & Talyawalka@Barr Hw (425018) \\
9 & Manilla @ D/S Split Rock (419043) & Namoi @ Manilla (419022) \\
10 & Namoi @ Mollee (419039) & Namoi @ D/S Gundigera Weir (419059) \\
11 & Namoi@ Bugilbone (419021) & Namoi @ Goangra (419026) \\
12 & Narran@ @ilby Wilby (422016) & Narran@ Narran Park (422029) \\
13 & Macintyre Brook@ Inglewood (416402C) & Macintyre Brook at Booba Sands (416415A) \\
14 & Goulburn River @ Murchison (405200) & Goulburn River @ McCoys Bridge (405232) \\
\hline & &
\end{tabular}

\section{DATA AND METHODS}

For each reach the data availability at the upstream, downstream, tributary and intermediate gauges was assessed to determine two periods for use in the two fold approach for calibration and validation. Based on the over lapping period of record at the upstream and downstream gauging stations, two equal periods were selected for each test reach.

Three main steps are used for testing the calibration of the routing parameters. These are:

1. Determination of index flows

2. Determination of travel time for different index flows

3. Determination of the skill of routing calibration compared to a benchmark model.

The implementation of the variable parameter Muskingum routing approach is described

in

https://wiki.ewater.org.au/display/SD43/S torage+routing.

\subsection{Determining index flows}

The piecewise storage function used by variable parameter Muskingum routing requires a series of relationships between flow and travel time to be defined. A series of index flows need to be identified and then the corresponding travel times determined.

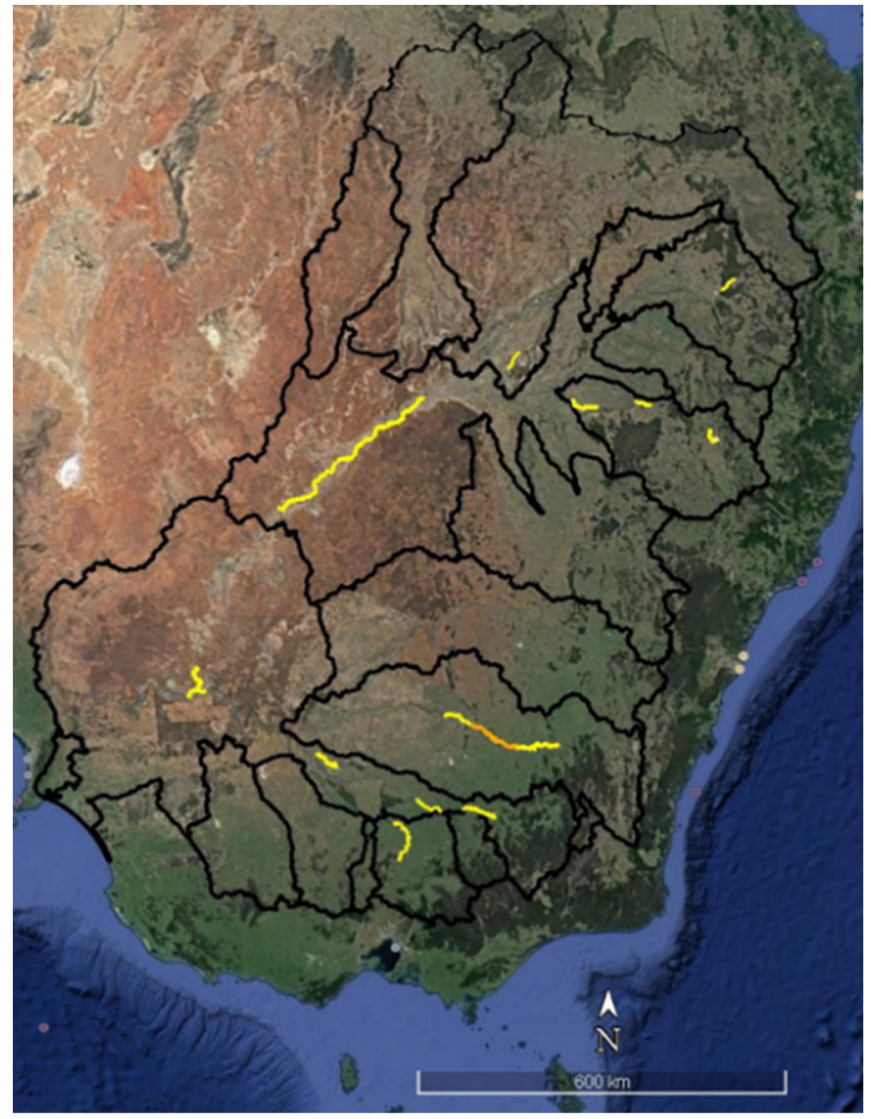

Figure 1. Location of test reaches used in analysis

There are a number of approaches that can be used to determine the index flows. These include, but are not limited to (i) evenly spaced flow intervals, (ii) index flows based on fitting a piecewise relationship to the rating curve, (iii) index flows based on manual selection of points from a cross section, (iv) index flows based on manual selection of point from a rating curve. In this paper we look at the comparison of evenly spaced flow 
intervals, with manual and automated selection of flows from the rating curve. In line with Close (1996), it was decided that a maximum of 10 index flows would be used and the inflow bias has been set to 1 .

\section{Evenly spaced flow intervals}

These have been determined by looking at the flows during the calibration period. The maximum flow has been set $10 \%$ above the maximum observed flow in calibration period. The minimum has been set at 0 . Eight index flows are then evenly spaced between these minimum and maximum values in linear space to return 10 index flows that cover the range of flow values in the calibration period.

\section{Manual selection of index flows}

This involves the selection of 10 index flows by a modeller. For this exercise the manual section of the index flows was based on an assessment of the upstream rating curve and where available the cross section.

\section{Automated selection of index flows from rating curve}

This approach automates the selection of index flows, while trying to capture the changes in the rating curve (which are assumed to represent changes in the river channel). The automated process:

- Determines the 3 largest flow events from the whole period of record

- Cuts the rating curve down to the flow values between the lowest value and the third largest flow event

- Six points are then fitted between the lowerst value on the rating curve and the third largest flow event, these points are adjusted to return a piecewise linear fit to the rating curve. This gives eight index flows. The maximum flow value and a point $10 \%$ above the maximum flow value are then used to define the 9th and 10th index flows.

\subsection{Determining travel times}

For all methods the following is assumed that: (1) the travel time for the first two index flows should be identical, (2) the travel time for the last two index flows should be identical and (3) high flows should be set based on observed flow data, not by optimisation.

Four different methods for determining the travel time are compared these are, (a) the automated selection of travel times based on analysis of upstream and downstream gauges, (b) determination of the travel time using optimisation.

\section{Automated selection of travel time based on analysis of peaks at the upstream and downstream flow gauges}

The selection of travel times was automated by:

- The hydrologist setting minimum and maximum plausible travel times for the reach

- For each peak in the upstream flow record, a corresponding peak is looked for in the downstream flow record within the minimum and maximum travel time bounds

- For each index flow, the travel time is determined by taking the mean and median of the peaks that fall within $10 \%$ either side of the index flow.

- Where, there are no flows in the range of the index flow, the travel time is set to the value of the pervious index flow.

This automated analysis of peaks, resulted in two different travel time estimates for each index flow,. One based on the mean and one on the median of the travel times of the different flow events.

\section{Optimisation of travel times}

The shuffle complex evolution optimiser (Duan et al. 1992) has been used with two different objective functions to determine the travel times between the upstream and downstream gauges for the different reaches. The two objective functions considered are both based on the Pearson correlation coefficient (R). The correlation coefficient has been used, as we are looking to achieve the best correlation between the observed downstream flow and the predicted downstream flow following the estimation of the routing parameters. The two objective functions used in optimisation are $\mathrm{R}$ and $\mathrm{R}$ on the $\log$ of the flow values.

By using two different objective functions we end up with two different travel time estimates for each index flow. In total for each index flow we end up with four different estimates of travel time for each index flow. 


\subsection{Determining the skill of routing calibration compared to a baseline}

To assess the predictive skill of our different routing models the reaches were simplified to a single reach, with an upstream and downstream gauge. This configuration was used to test the different index flow methods and estimation of travel time. The skill score (Murphy1988) of each method for setting routing parameters was tested based on comparison to a benchmark model (Equation 1).

The benchmark model used in this paper is:

Downstream flow $=$ Upstream flow lagged by $\mathrm{x}$ days, where $\mathrm{x}$ achieves the maximum value for $\mathrm{R}$ when comparing observed and modelled flows at the downstream gauge

Skill Score $=\frac{R_{\text {model }}-R_{\text {benchmark }}}{1-R_{\text {benchmark }}}$

Equation 1

\subsection{River system models}

River system model for each test reach were developed using eWater Source (Welsh, et al., 2012). Optimisation of the travel times was undertaken externally to eWater Source, and the optimised travel times and index flows were fed back into the eWater Source model to generate the predicted flows at the downstream gauge. Accounting for the different combinations of index flows and travel times, the eWater Source model for each reach was run for 12 different test cases.

\section{RESULTS}

Results from the validation periods were used to determine how well the different methods were able to make predictions at the downstream gauge. The results have been assessed in terms of the $\mathrm{R}$ value and the skill scores. To determine if there is a statistical different between the results for each method, the Student's t-test has been used to see if there is a difference between the skills scores for each of the different methods tested. .

\subsection{Assessment of overall routing calibration.}

Figure $2 \mathrm{a}$ shows the $\mathrm{R}$ values and range of skills scores for each river reach. It should be noted that when $\mathrm{R}$ values are very close to 1 (e.g. Reach 1 and Reach 4 ) and very small increase in the $R$ values may equate to a large skills score. Figure $2 \mathrm{~b}$ shows that for 13 of the 14 test reaches all methods tested showed an improvement in the $\mathrm{R}$ score compared to the benchmark model.
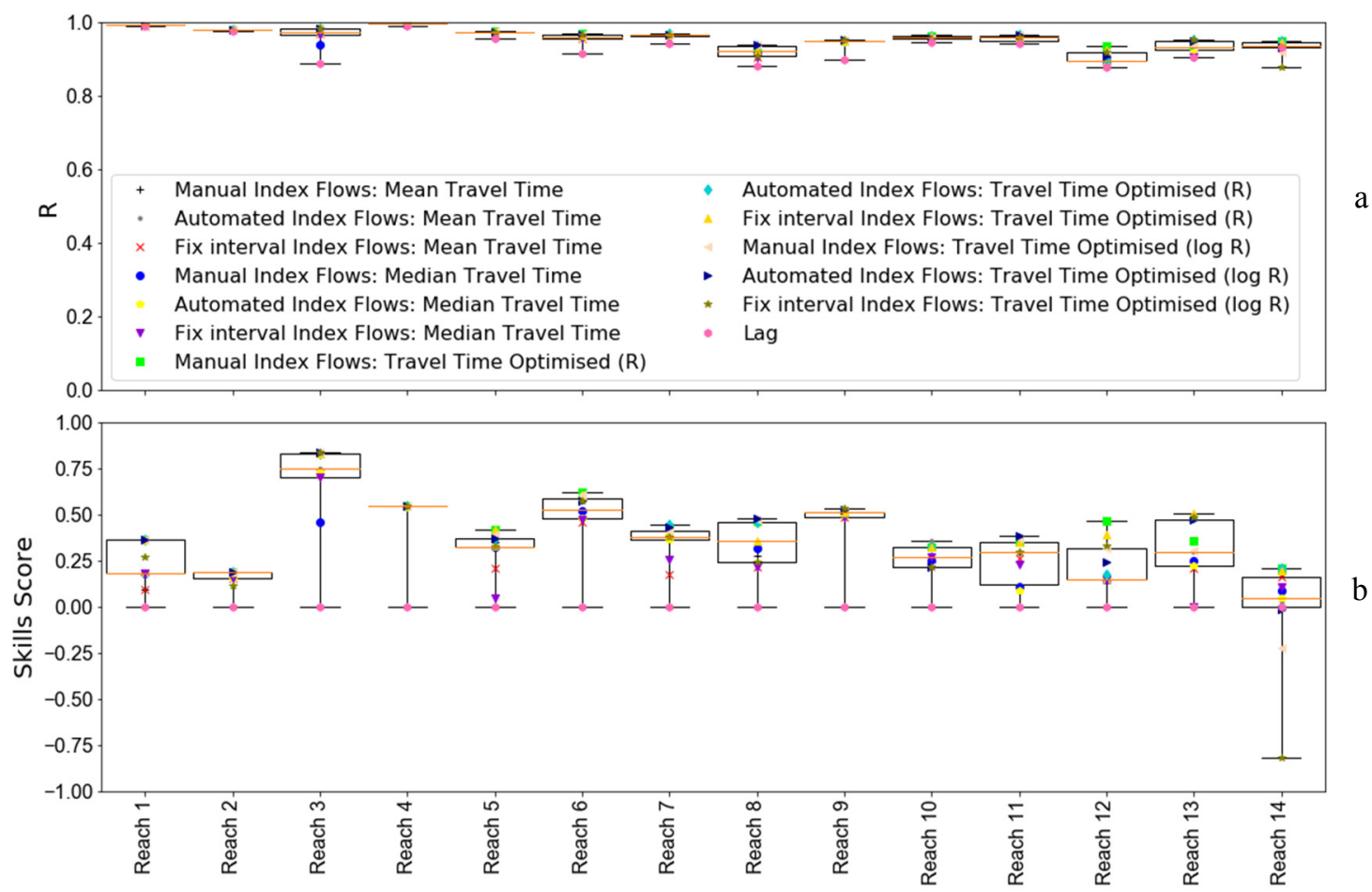

Figure 2. R values (a) and, Skills score (b) by Reach for the validation period 
Figure 3 compares the $\mathrm{R}$ values and skills scores based on the different combinations of method for index flows and travel times. Figure $3 \mathrm{a}$ reports the $\mathrm{R}$ values, and shows that there is very little difference between the different methods. Figure $3 \mathrm{~b}$ shows the results of the skill scores for each method. When the skills scores are compared to the benchmark model all methods are statistically different at the 0.01 level. When we test for statistical differences between the methods we find that there are no statistical difference between the $\mathrm{R}$ values for all method. However, when looking at the skills scores at the 0.05 level the Student's t-test indicates that there is a difference between optimisation using $\mathrm{R}$ as an objective and the methods based on analysis of peaks.

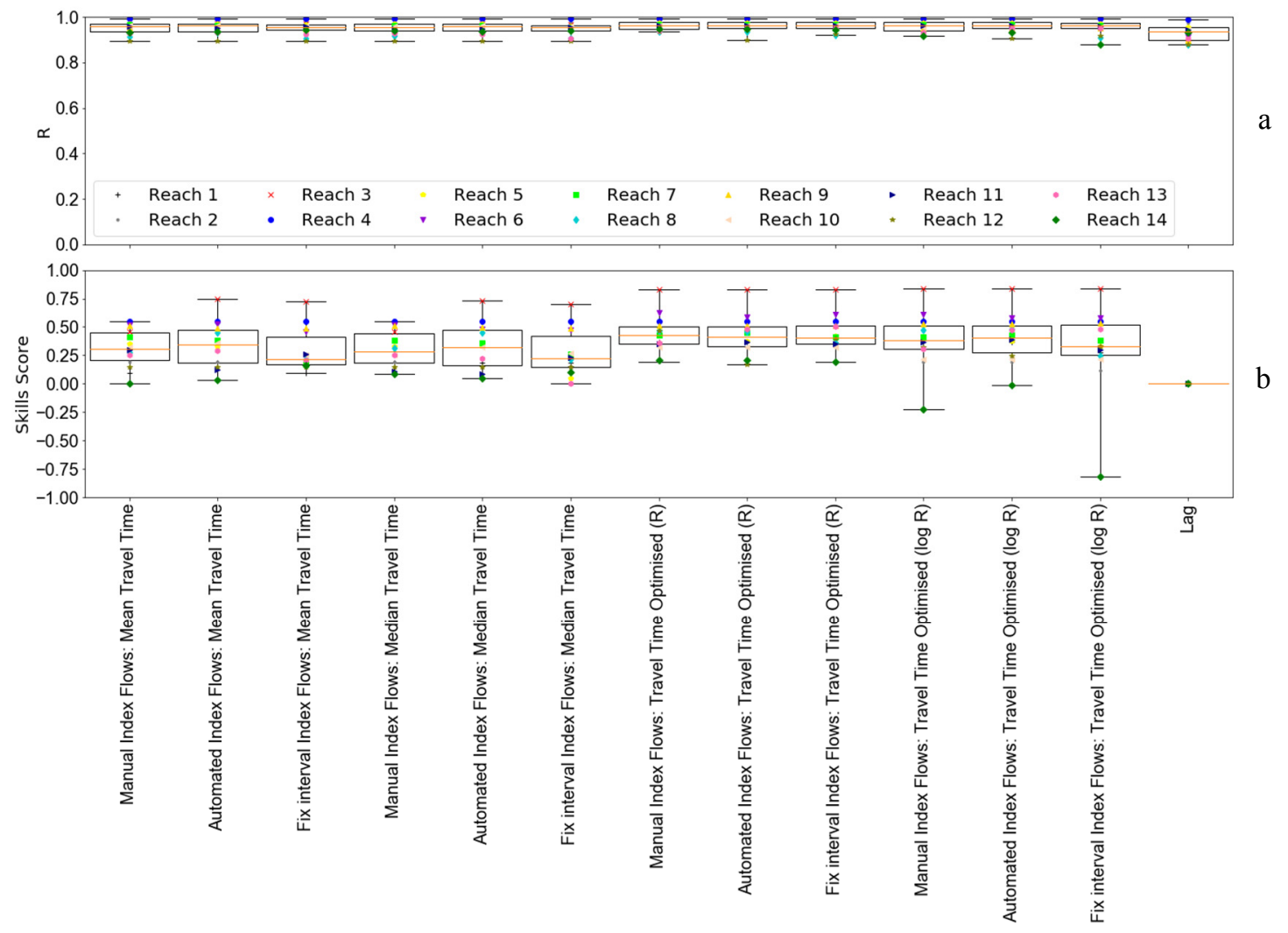

Figure 3. R values (A) and skills scores (B) by method for validation periods.

\subsection{Setting index flows and determining travel times}

There was no statistical difference between any of the methods tested for setting index flows at either the 0.01 or 0.05 level using the Student t-test for both the $\mathrm{R}$ values and the skills score during the validation period.

Regarding the different methods for determining the travel times, there was no difference between any of the methods tested at either the 0.01 or 0.05 level using the Student's t-test on the R values. Using the Student's t-test comparing the skills scores, there was a statistical difference at the 0.05 level when comparing the optimisation using $\mathrm{R}$ as an objective function to the methods using analysis of peaks. At the 0.01 level there was is no difference between the methods.

\section{DISCUSSION AND CONCLUSIONS}

The results indicate that optimisation has the potential to compensate for issues associated with the selection of index flows. This is supported by the statistical difference at the 0.05 level shown between the skills scores when using fixed intervals combined with analysis of peaks vs. fixed intervals combined with optimisation. The results indicate that there is no method that consistently outperforms other methods during the validation period. The results however do indicate that, (1) fixed intervals are not a good way to determine the index flows, (2) in 13 of the 14 reaches used in this analysis all methods improved that prediction of flows at the downstream gauge compared to the benchmark model, (3) depending on the reach the determination of routing parameters can be undertaken in various ways to achieve similar outcomes. This work is consistent with that 
of Fernando et al. (2007) which concluded that automated calibration can produce a good set of parameters without any a priori knowledge of the system.

While this work has not demonstrated that one particular method consistently outperforms the others during the validation period. It does allow us to make some recommendations around a preferred practice. The key recommendations are: (1) Fixed intervals should not be used to set index flows; (2) Selecting the points of change in the upstream rating curve provides a reasonable method to determine the index flows; (3) Travel times can be set by either optimisation or analysis of peaks; (4) High flow travel times should be set based on observed travel times.

\section{REFERENCES}

Close, A. (1996). A new daily model of flow and solute transport in the River Murray. Proc. 23rd Hydrology and Water Resource Symposium. Hobart, 21-24 May: 173 - 178.

Fernando et al. (2007). Assessing Prediction Uncertainty in the BIGMOD Model A Shuffled Complex Evolution Metropolis Algorithm Approach. MODSIM December 2007.

Hogue, T. S., Sorooshian, S., Gupta, H., Holz, A., \& Braatz, D. (2000). A multistep automatic calibration scheme for river forecasting models. Journal of Hydrometeorology, 1, 524 - 542.

Hughes, J. D., Dutta, D., Vaze, J., Kim, S. S., \& Podger, G. M. (2014). An automated multi-step calibration procedure for a river system model. Environmental Modelling and Software, 173 - 183.

Koussis, A. (2009). Assessment and review of the hydraulics of storage flood routing 70 years after the presentation of the Muskingum method. Hydrological Sciences Journal, 54:1, 43-61, DOI: 10.1623/hysj.54.1.43.

Murphy, A. H. (1988). Skill scores based on the mean square errot and their relationship to the correlation coefficient. Monthly Weather Review, 116, 2417 -2424.

Welsh, W. D., Vaze, J., Dutta, D., Rassam, D., Rahman, J. M., Jolly, I. D., \& Lerat, J. (2012). An integrated modelling framework for regulated river systems. Environmental Modelling and Software, DOI 10.1016/j.envsoft.2012.02.022.

Wong, T. H., \& Laurenson, E. M. (1983). Wave Speed-Discharge Relations in Natural Channels. Water Resources Research, 701-706. 